\title{
Student Mobility in North African Countries and the Need for an Information System for its Management
}

\author{
Majida Laaziri ${ }^{1}$, Khaoula Benmoussa ${ }^{1}$, Samira Khoulji ${ }^{1}$ and Kerkeb Mohamed Larbi ${ }^{2}$ \\ ${ }_{1,2}$ Information System Engineering Resarch Group \\ ${ }^{1}$ National School of Applied Sciences of Tetouan. \\ ${ }^{2}$ Faculty of Sciences of Tetouan. Abdelmalek Essaâdi University \\ majida.laaziri@gmail.com, Benmoussakhaoula24@gmail.com,khouljisamira@gmail.com, \\ kerkebml@gmail.com
}

\begin{abstract}
University cooperation is a major concern in North Africa as in the rest of the world. Indeed, the cooperation of the universities of these countries with their counterparts abroad is very active. The number of actions identified for the countries of North Africa is higher than that recorded for the countries of sub-Saharan Africa as a whole. This means that these countries have thirsted for openness to the world and knowledge. Several partnership programs fund cooperation actions with higher education institutions in North Africa and encourage student mobility, which is a source Enrichment for the education system. In North Africa, the mobility of students, researchers and staff constitutes a great wealth for the education system and one of the essential dimensions of the internationalization of higher education.

Student mobility is of great importance at the heart of the missions and strategic plans of universities, as an essential criterion to take into account from the point of view of the evolution of the university system. It is seen as a policy instrument that globally links higher education systems and promotes the flow of talent and the development of a highly skilled workforce. Mobility presents crucial issues not only in the academic Also in the education of citizens open to the world and to society.
\end{abstract}

As a result, international mobility is a linguistically and culturally essential experience for students, but it is a discontinuity in their academic curriculum. International mobility is favored by states; it is a wealth both for countries of departure and destination

This article analyses the incoming and outgoing mobility of foreign students from and to the countries of North Africa. This mobility is massive; its rate is notoriously one of the highest in the world since the late 1980s. It involves interactions between students and researchers at international level and it is also a vehicle for knowledge exchange and a criterion for developing the potential for research and innovation, and Improvement of the performance of the higher education system in North Africa.

This article also provides the basis for a cooperative information system capable of managing the inbound and outbound student mobility flows of these countries. 
Majida Laaziri, Khaoula Benmoussa, Samira Khoulji and Kerkeb Mohamed Larbi, Student Mobility in North African Countries and the Need for an Information System for its Management. Transactions on Machine Learning and Artificial Intelligence, Vol 5 No 4 August (2017); p: 761-767

\section{Introduction}

The concept of the internationalization of higher education is constantly evolving. As this has created new responses to the challenges of globalization, and the universities have entered into more complex international relations, the concept has ceased to refer only to international education in order to integrate the international dimension into curricula And institutional culture.

Internationalization promotes the cooperation and integration of universities with their peers abroad; these links of academic cooperation make it possible to establish relations and networks, exchange experiences and good practices, and Generation of ideas and knowledge. It facilitates the transfer of technology, innovation and the strengthening of scientific capacities in countries[1-3].

From exchange comes enrichment. A mutual enrichment promotes excellence through student mobility, technological transfer, innovation transfer, the pooling of good practices and the mobility of teachers, researchers and staff.

In North Africa and elsewhere in the world, the mobility of students, researchers and staff constitutes a great wealth for the education system and one of the essential dimensions of the internationalization of higher education.

\section{Study abroad}

In addition to the skills specific to the professional field envisaged, the experience of training abroad is a major cultural asset for university students, and makes the difference in any approach to professional integration.

Participation in a program of studies or internships abroad is an appreciable opportunity for encounters, a factor of maturity, development of personal qualities of openness, language development, autonomy, and on the academic level, a new method of learning. Expatriation, even temporary, can be considered as a career accelerator.

There are several starting options for a student wishing to perform an international mobility during his studies. The various ways of exploring the world vary from one university to another; To date, students enrolled in a university program may leave their university either through an inter-university exchange, internship, language development, practical or field course, A dissertation or a thesis, a research or a completely autonomous way to pursue a program offered abroad.

\section{Student mobility}

Student mobility is of great importance at the heart of the missions and strategic plans of universities, as an essential criterion to take into account from the point of view of the evolution of the university system. It is seen as a policy instrument that globally links higher education systems and promotes the flow of talent and the development of a highly skilled workforce. Mobility presents crucial issues not only in the academic Also in the education of citizens open to the world and to society.

As a result, international mobility is a linguistically and culturally essential experience for students, but it is a discontinuity in their academic curriculum. International mobility is favored by states; it is a wealth both for countries of departure and destination[4-6]. 


\section{Motilities Cooperation projects for the countries of North Africa}

There is today a real need for education, training, mobility and integration of young people in the countries of North Africa. Youth in these countries is confronted with the difficulties of professional integration. The youth unemployment rate is at an alarming level.

For this reason, it is now necessary to strengthen the academic cooperation between the countries of North Africa and other international countries in order to promote student mobility at all levels of education. These co-operative links are aimed at fostering the improvement and modernization of higher education systems, as well as vocational training systems through exchanges of good practice, mobility and cultural exchanges.

These cooperative links with other international countries are essentially in a multilateral framework with the support of the European Union, which finance programs and projects for cooperation with the countries of North Africa that promote student mobility. Such as Erasmus Mundus, the OMJ, Tempus projects 2008-2013, etc. [7-9].

These cooperative programs offer scholarships for students pursuing their studies abroad, aim to increase mobility and cooperation, promote the development of higher education systems, but also facilitate the process of economic and social reform, And development in partner countries.

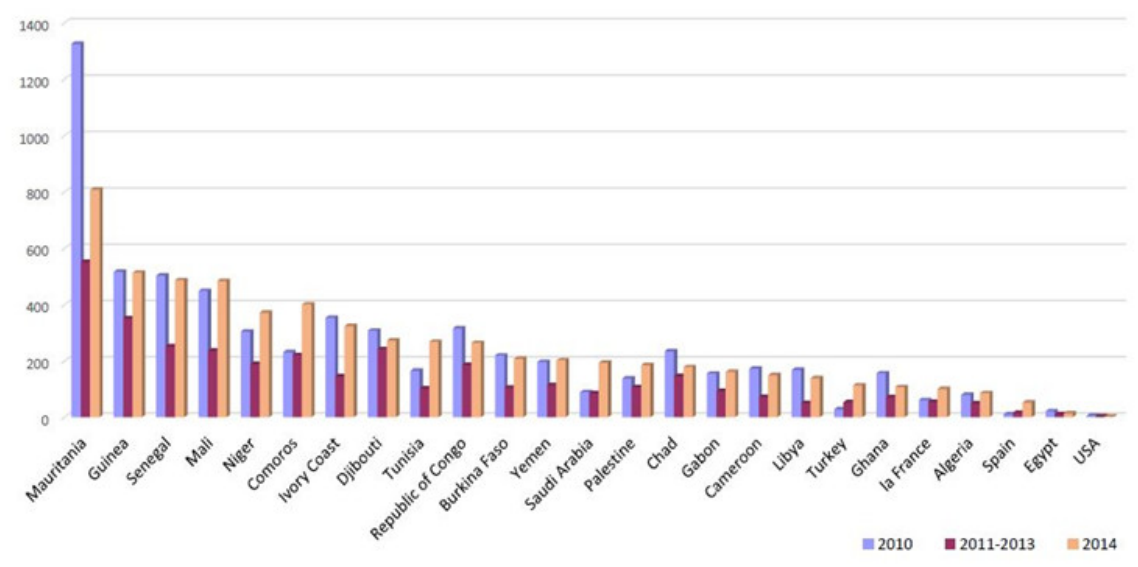

Figure 1 : Incoming Student Mobility in Morocco

\section{Incoming and Outgoing student mobility in the countries of North Africa: case of Morocco, Tunisia, and Algeria.}

\subsection{Incoming and outgoing student mobility in Morocco}

\subsubsection{Incoming student mobility}

In terms of Incoming mobility of foreign students, Morocco has been a country of student expatriation for several years. This mobility is massive, its rate is notoriously one of the highest in the world since the late 1980s, it has become a highly coveted country by foreign students from almost all walks of life[10-11].

On the side of international students hosted, and according to UNESCO statistics, Most of the mobility students in Morocco come from sub-Saharan Africa: Mauritania, Guinea, Senegal, Mali and Nigeria. These students benefit from the cooperation agreements signed with Morocco, offering scholarships to African students. These agreements represent the main part of the Moroccan-African cooperation whose 
Majida Laaziri, Khaoula Benmoussa, Samira Khoulji and Kerkeb Mohamed Larbi, Student Mobility in North African Countries and the Need for an Information System for its Management. Transactions on Machine Learning and Artificial Intelligence, Vol 5 No 4 August (2017); p: 761-767

objective is to promote economic and commercial relations between Morocco and its African space and to improve its political position on the continent.

\subsubsection{Outgoing student mobility}

Outgoing student mobility is necessary for scientific excellence, which involves interactions between students and researchers at international level, it is also a vehicle for knowledge exchange and a criterion for developing the potential for research and innovation, and Improvement of the performance of the higher education system in Morocco.

According to statistics from the UNESCO database, Morocco ranks among the top countries of origin of mobile students in the Mediterranean region, and ranks third behind France and Turkey. France is by far the destination of the Mediterranean area most appreciated by Moroccan students in front of Spain, Germany, Ukraine, Italy and Canada. These countries offer scholarships to young university graduates, teachers and researchers in all branches of science, as well as in the fields of music and the visual arts.

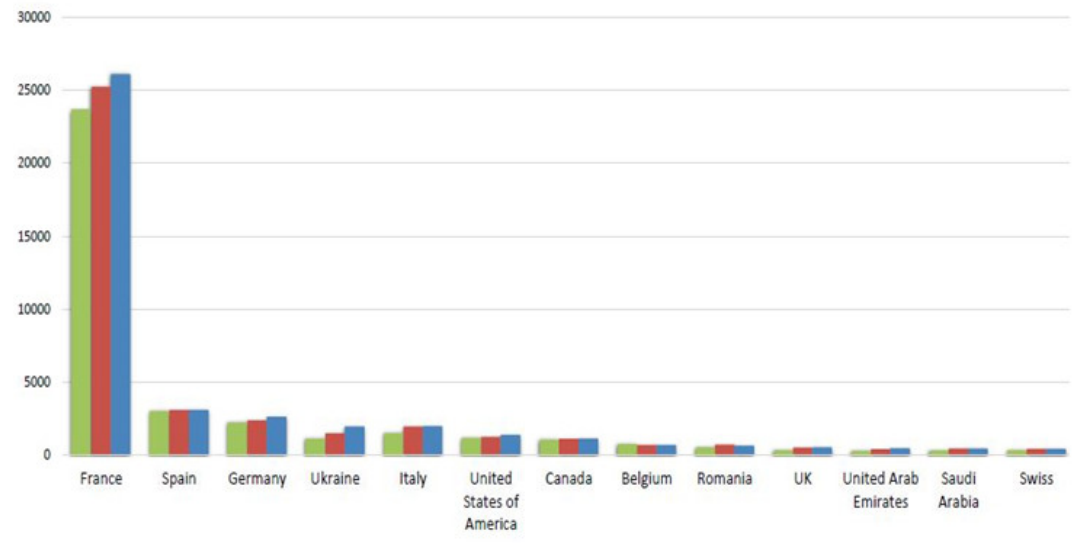

Figure 2 : Outgoing Student Mobility of Morocco

\subsection{Incoming and outgoing student mobility in Tunisia}

\subsubsection{Incoming student mobility}

In recent years, the Tunisian higher education system has achieved a remarkable qualitative leap, thanks to the reforms undertaken which have made it possible to equip all the regions with university institutions and to create a network of universities developing scientific research components. Moreover, the teaching is free and mainly taught in French, which attracts foreign students, especially from francophone Africa. Finally, the post-revolutionary government has developed a policy of attractiveness to the countries of sub-Saharan Africa, which has increased the number of foreign students continuing their studies in Tunisia. Most of these students come from Congo, Libya, Mali, Cameroon, Mauritania, Côte d'Ivoire and Maghreb countries such as Morocco[10-11]. 


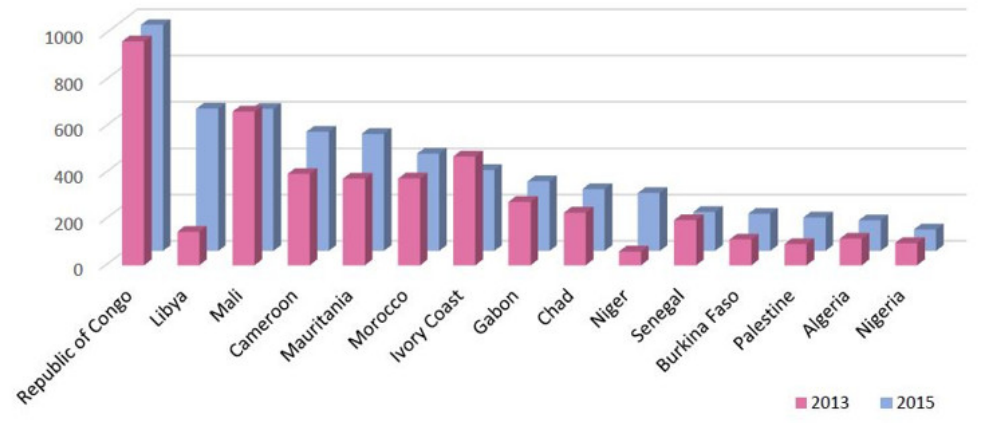

Figure 3: Outgoing Student Mobility of Morocco

\subsubsection{Outgoing student mobility}

The presence of foreign students in universities abroad is a source of enrichment and cultural creativity in Tunisia. Most Tunisian students are still attracted mostly by France, thanks to the use of French and the Tunisian higher system, which is strongly inspired by the French system, which greatly facilitates the temporary mobility of Tunisian students to France, as well as The setting up of partnerships and double degrees. After France comes Germany as the second host country for Tunisian students, using its scholarship and research programs for Tunisian students and researchers. After that, Romania was ranked third, followed by Canada, Italy, United States, Ukraine, Switzerland and Middle-Eastern countries such as Saudi Arabia.

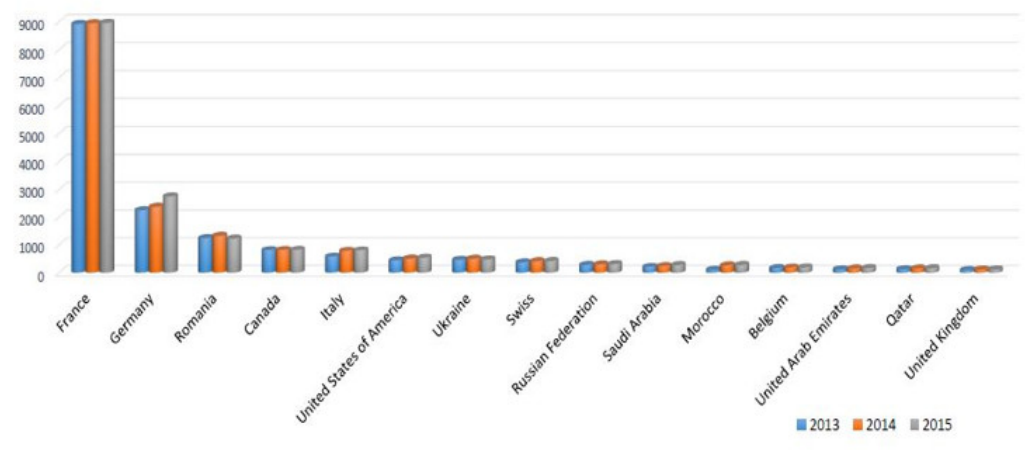

Figure 4 : Incoming Student Mobility in Tunisia

\subsection{Incoming and outgoing student mobility in Algeria}

\subsubsection{Incoming student mobility}

For incoming mobility in Algeria, Algeria welcomes an increasing number of international mobility students studying in Algerian higher education institutions according to Unesco statistics. The distribution of these students by country of origin is not available in the UIS statistical database on mobility, but most of these students are probably from sub-Saharan Africa and come from Botswana, Burkina Faso, Burundi, Cameroon, Chad, Congo, Côte d'Ivoire, etc. [10-11].

\subsubsection{Outgoingstudentmobility}

For the outgoing mobility of Algeria according to Unesco statistics (UIS), it is almost exclusively geared towards France, which receives almost $90 \%$ of the total number of Algerian students in mobility. Outside 
Majida Laaziri, Khaoula Benmoussa, Samira Khoulji and Kerkeb Mohamed Larbi, Student Mobility in North African

Countries and the Need for an Information System for its Management. Transactions on Machine Learning and Artificial Intelligence, Vol 5 No 4 August (2017); p: 761-767

France, the 2nd Position is for Canada, thanks to its good bilateral relations with Algeria, and the common use of the French language representing a factor of rapprochement between the two countries. In the 3rd position comes Saudi Arabia and the United Arab Emirates with their economic relations, followed by Malaysia, Belgium, Spain which has put in place agreements to develop trade with Algeria. The United States of America, Italy, ...

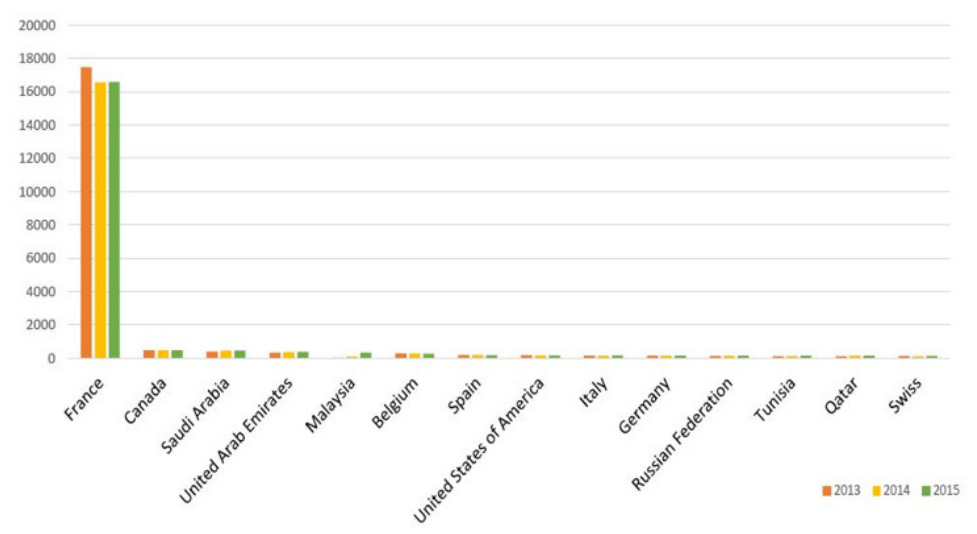

Figure 5: Outgoing Student Mobility of Algeria

In order for a university or country to achieve high levels of performance in terms of student mobility, it needs to improve the efficiency of their cooperation and partnership actions. An information system is a tool that can be used in order to achieve high levels of efficiency in monitoring and evaluation of this kind of actions.
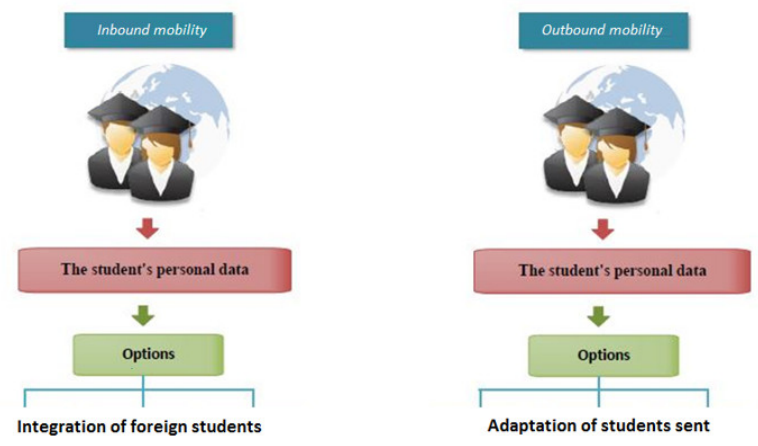

Figure 6: inbound or outbound mobility

Information systems can be used to create new services aux administrators staff and also an entirely new cooperation model. Such model can describes how an university produces, delivers and how they sell a product or service to create wealth.

Such a model describes how a university establishes co-operative relationships with other institutions of higher education, how it sends and receives students, and how it monitors these students in order to to succeed the decided mobility. 
We developed an information system capable of providing real-time data on the situation of students who benefited from inbound or outbound mobility. This system was designed in consultation with all the players involved in student mobility in North African countries.

\section{Conclusion}

In the context of the globalization of academic competition, international exchanges are of a strategic nature for research and higher education in Europe and in North Africa.

University mobility is now a must. Creator of culture and open-mindedness, a key element of academic success and of professional integration, it is a tremendous lever for the recognition and international influence of universities, Position in the global race to excellence ... and also to make it known.

\section{REFERENCES}

[1] Laure Endrizzi, “ La mobilité étudiante, entre mythe et réalité”,2010.

[2] Brian D. Denman, «La Gestalt revisitée: retombées et évaluation de la coopération universitaire internationale », Politiques et gestion de l'enseignement supérieur, 1/2004 (no16), p. 73-92.

[3] Eric Gobe, Catherine Marry, Fran, coiseChamozzi. "Mobilités internationales et attaches familiales des diplômes maghrébins de grandes écoles ». Sociologies, Toulouse : Association internationale des sociologues de langue française, 2013, pp.1-15.

[4] Abdelwahab Hafaiedh, "La mobilité internationale des étudiants tunisiens: Aide publique et mobilité institutionnelle»,2007.

[5] Nathalie Havet, " Mobilité internationale des étudiants du supérieur et débuts de vie active ", 2013 Catherine Agulhon, Ridha Ennafaa, "Les étudiants étrangers. Des trajectoires spécifiques ? ». Les vies étudiantes. Tendances et inégalités, La Documentation française, 2016, 978-2-11-010267-6.

[6] Sylvie Mazzella. "Introduction. Une "libéralisation d'Etat" de l'enseignement supérieur ?: Mutation internationale et évolution maghrébine »,Maisonneuve et Larose. L'enseignement supérieur dans la mondialisation libérale, Karthala, pp.356, 2008, IRMC, 978-2-7068-1990-2.

[7] Terrier Eugénie, «Les migrations internationales pour études : facteurs de mobilité et inégalités NordSud », L'Information géographique, 4/2009 (Vol. 73), p. 69-75.

[8] Souley Mahamadou Laouali et Jean-Baptiste Meyer, "Le Maroc, pays d'accueil d'étudiants étrangers ", Hommes et migrations, 1300 | 2012, 114-123.

[9] Livre blanc, « Coopération Universitaire pour Le Développement entre l'Afrique et l’Europe : Relever Les défis régionaux et globaux ».

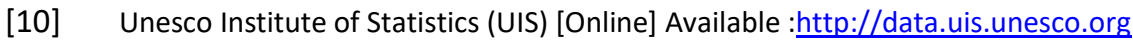

[11] International student mobility [Online] Available:http://www.uis.unesco.org 